\title{
An Investigation into Factors Demotivating Students in EFL Learning at Tertiary Level
}

\author{
Le Van Tuyen, Dang Ngoc Cat Tien*
}

\author{
Ho Chi Minh City University of Technology (HUTECH)-Vietnam \\ Yersin University of Dalat-Vietnam \\ *Corresponding author
}

\begin{abstract}
Nowadays in Vietnam English is a compulsory subject for all students at tertiary level. Students are required to be able to use the language well after graduation. However, it is not really easy for all of them to meet the requirements and expectations of both institutions and society. Although most of them may be motivated in learning English, many factors may affect their learning. The major aim of this study was to investigate the factors that demotivate the students in learning English as a foreign language (EFL) at a private university in Da LatCity-Vietnam (Henceforth called PUD). It also attempted to explore what strategies might be adopted to overcome demotivating factors in the English classroom.200 non-English majored students of PUD participated in the study. Both qualitative and quantitative data was collected for the study. The research instruments employed for collecting data were the questionnaire and interview. For analyzing the collected data, content analysis, factor analysis and descriptive statistics were used. The findings of the study revealed that among teacher-related, classroom-related, and student-related factors, the student-related factors affected the students the most. Furthermore, the findings of this study explored the students' perspectives of several strategies which might be used in classto help both students and teachers reduce demotivating factors in EFL learning.
\end{abstract}

Keywords - tertiary level, demotivating factors, English learning, strategies.

\section{INTRODUCTION}

Motivation is one of the key factors that influence students' achievement of learning a language as stated byMcDonough (1983).In contrast with motivating factors, demotivating factors are assumed to be neglected in studies on language teaching and learning, especially in EFL contexts. Demotivating factors involve many factors like teacher's personality and behavior, teachers' competence, lack of modern teaching materials, lesson content, reduced self-confidence, lack of relaxed classroom environment and assessment. Demotivation has a negative impact on students, preventing them from gaining expected learning outcomes (Tran \& Baldouf, 2007). The impact of demotivating factors is more serious when English language learning takes place in a context like Vietnam. That is because Vietnamese students do not have many opportunities to contact native speakers meanwhile a variety of factors influence their learning. Obviously, it is very important to be awareof the factors that demotivate the students. So far a variety of studies in the international context have been conducted to investigate factors that demotivate EFL students in their learning such as (Kikuchi \& Sakai, 2009; Meshkat \& Hassani, 2012; Hamada \& Grafström, 2014; Khouya, 2018), or in the Vietnamese context such as (Tran\&Baldauf, 2007; Hoang, 2016). It is undeniable that little research has been conducted to investigate demotivating factors affecting students in learning EFL in the Vietnamese context; especially no literature relating to demotivating factors has been found within the context of PUD. That is why this study attempts to fill this gap.

\section{PURPOSES OF THE STUDY}

The main purpose of this study is to investigate factors that demotivate studentsin learning EFL at PUD. More specifically, it attempts to discover what factors that demotivate students in learning EFL at PUD; and find out what strategies may be employed to overcome demotivating factors in the EFL classroom from the students' perspectives.

\section{RESEARCH QUESTIONS}

This study attempts to address the following two research questions.

1. What are the factors that demotivate students at PUD in EFL learning?

2. What strategies may be employed to overcome demotivating factors in EFL clas srooms? 


\section{SIGNIFICANCE OF THE STUDY}

The findings of this study are expected to provide significant contributions at both theoretical and practical levels. Theoretically, it is expected that the findings of this study will partly contribute to the literature of motivation and demotivation in foreign language learning in the context of Vietnamese higher education. This contribution may help researchers reaffirm the fact that motivation is considered to be an important factor contributing to the success of learning a foreign or second language (Dörnyei, 2009), and that demotivating factors can have negative effects on students' learning. Practically, first, this study will provide useful information about what factors demotivate students' learning, and possible ways to enhance students' motivation to learn EFL at PUD. The findings of the study can be used as a useful reference for lecturers in helping students to be more confidence, and eventually improve students' positive learning motivation. Second, this study can become a reliable source of reference for other researchers in the same field. Finally, the findings may help to improve the quality of the teaching and learning English in tertiary level in Vietnam.

\section{A BRIEF REVIEW OF LITERATURE 5.1 Motivation and Demotivation}

So far researchers have defined motivation and demotivation in several ways. Regarding motivation, Brown (1987) defines that motivation is commonly thought of as "an inner drive, impulse, emotion, or desire that moves one to a particular action"; or Rogers (1986) notes that motivation is "those factors that energize and direct behavioral patterns organized around a goal. In educational contexts, Schunk (1996) presents four elements that define the concept of motivation: excitement, appropriateness, expectation, and outcome. Wigfield and Eccles (2000) argue that learning motivation is a perception of the value of learning and the expectations of students for specific learning purposes. In general, motivation is something that prompts a person to accomplish his or her goal and aim. It creates the needs of learning to improve their knowledge and skills. It is one of the strongest influences on students' attitudes and achievement.

In terms of demotivation, Dörnyei and Ushioda (2011) describe demotivation as the dark side of motivation; it is the 'specific external forces that reduce or diminish the motivational basis of a behavioral intention or an ongoing action'. Accordingly, demotivation in limited to external factors whereas Sakai and Kikuchi (2009) claim that the demotivation should include both external and internal factors. While motivation is extremely important to learning, demotivation is a common problem for students at all levels (Ersöz, 2004).It can be said that motivation is the desire to guide students toward their learning goals; demotivation is the lack and the loss of the des ire due to some factors; and thus resulting in students being unable to achieve their learning goals or improve their skills.

\subsection{Factors demotivating students in learning foreign languages}

Three major factors that may demotivate students in their foreign language learning are teacher-related factors, student-related factors and class-room related factors. Regarding teacher-related factors, it is believed that students' demotivation is directly affected by the teacher. The impact of teachers on students' demotivation may include: (a)inappropriate teachers' behaviors and attitudes which are considered as the main factor causing learners' demotivation (Chambers, 1993); (b) teachers' poor teaching methods which may have a negative effect on the students' willingness to learn. For example: some students find themselves bored due to the teachers' long explanations, their failure in giving interesting materials (Dornyei \& Ushioda, 2011); (c) teachers' negative feedback which may influence students' learning, make them lose interest or confidence (Griffing, 2006); and (d) teachers' unfair grading which is believed to have negative effects on students' motivation. If a student gets bad mark, especially when they feel that this mark is not fair for him / her, this will reduce his/her self-confidence, which may lead to demotivation eventually (Hamada, 2011).

In terms of classroom-related factors, several factors have been identified by researchers such as (a) inappropriate learning contents and materials which may cause demotivation in a variety of ways. Kikuchi \& Sakai (2009) conclude that course books and learning content are prominent demotivating factors.Obviously, if the content of the lesson is seen as uninteresting or considered boring and tedious by students; then, they will not be able to follow or concentrate on the lesson; (b) uncomfortable classroom environment which are related to classroom size, demographic factors, situations, technological learning tools in the classroom, climate, weather conditions, etc. If the classroom is too crowded and there is not enough light, it demotivates students, because it creates difficulty in studying due to troublesome. The tense climate of the second language environment causes anxietyamong second language students, and this anxiety factor negatively affects the learning of and motivation towards the second language (Young, 1999); and (c) inadequate equipment or technology is a factor that may cause demotivation. 
And finally, in respect to student-related factors, researchers mention such factors as (a) reduced selfconfidence which is caused by low self-efficacy, low proficiency, lack of competence or anxiety over making mistakes (Hamada, 2011). Therefore, reduced selfconfidence affects students' willingness to learn and can ultimately lead to loss of motivation; (b) lack of intrinsic motivation which may lead to demotivation. Lack of intrinsic motivation is certainly a significant demotivating factor in learning a foreign language. These negative feelings stem from the fact that engaging in the task is reluctant. When intrinsically demotivated, an individual does not engagein a task because he/she does not find the task enjoyable and pleasant. Such individuals tend to expend less effort on the task; (c) negative attitudes toward learning a foreign language which has a significant influence on the students' outcome. When a student has negative beliefs about language learning, he/ she will develop a negative attitude towards learning this particular language (Gardner \& MacIntyre, 1993).

\subsection{Strategies Used to Overcome Demotivating Factors}

L2motivationalteaching practiceis viewedas acyclicprocess, and is divided into four main dimensions (Dörnyei, 2001). The general motivational strategies which are relevant to this study are displayed in the following figure.

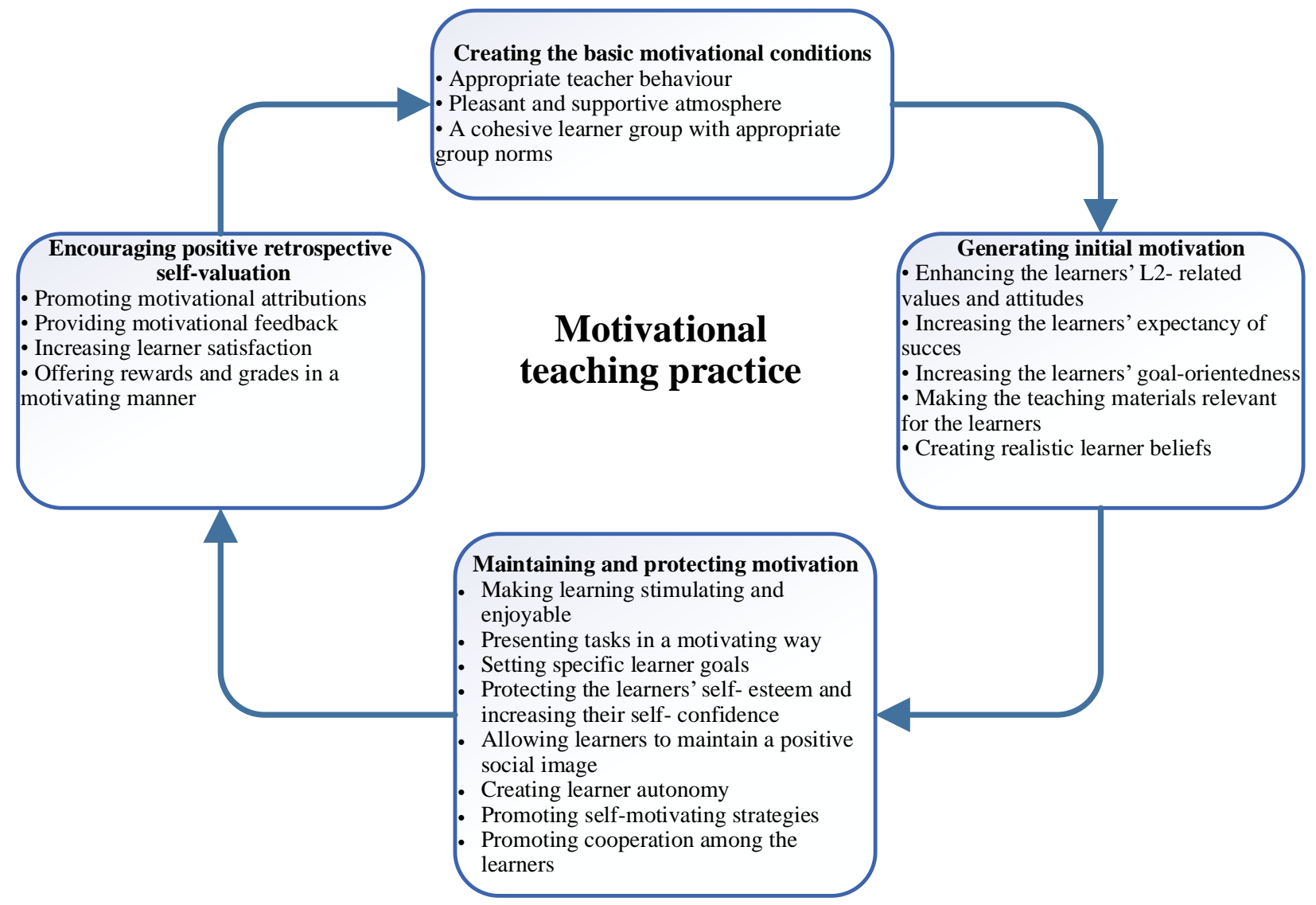

Fig.1: The Components of L2 Motivational Teaching Practice (Source: Dörnyei, 2001, p.29)

It can be seen in Figure 1 that there are four components, including creating the basic motivational conditions, generating initial motivation, maintaining and protecting motivation, and encouraging positive retrospective self-evaluation. Regarding creating the basic motivational conditions, Dörnyei (2001) suggests that some conditions should be created in the classroom in order to use motivational strategies effectively. These conditions are demonstrating appropriate teacher behavior, creating a pleasant atmosphere in the classroom and generating a cohesive student group. Regarding generating initial motivation, Brophy (2004)teachers need to actively generate positive student attitudes towards learning by enhancing students' language-related values and attitudes; increasing their expectancy of success; increasing their goal-orientedness; making the teaching materials relevant to them and creating realistic student beliefs.In terms of maintaining and protecting motivation, Wlodkowski (1985) states that 'any learning activity can become satiating'; therefore, teachers should use motivational influences to actively maintain and protect motivation during the learning process. Motivational strategies related to this area including presenting tasks in a motivational way, increasing the self-confidence of students, and promoting autonomous learning. In respect to encouraging positive self-evaluation, feedback given 
by teachers could influence students' motivation. Brophy (2004) indicates some qualities of motivational feedback such as appreciating achievements, showing confidence that eventual goals will be accomplished, and providing useful feedback that highlights the areas in which students need to improve. Dörnyei (2001) suggests different strategies which teachers could use to provide motivational feedback. For example, teachers should give prompt and regular feedback, and react to positive contributions from students. Also, students should be given self-assessment or peer grading to assess their learning and evaluate their own improvement and progress.

In conclusion, literature shows that motivation and demotivation partly decide whether EFL students succeed in their learning or not. Demotivating factors exist and usually have negativeeffects on students' learning. It is necessary for teachers to employ different strategies to overcome demotivating factors which may hinder students' learning.

\section{RESEARCH METHODS}

\subsection{Participants}

This study was conducted at PUD in Vietnam. 235 participants of this study were randomly selected among the whole population of about 1750 non-English major students.However, based on the number of the exactly and relevantly completed questionnaire copies returned to the researcher, the final actual number of the respondents was 200 students, accounting for $85 \%$ of the participants.The respondents majored in Business administration (34.5\%), Tourism management(26\%), Nursing(10.5\%),Architecture(9\%), Biology technology (9\%), Information technology (6.5\%), and Environmental science $(4.5 \%)$. Out of 200 respondents, 39\% were male and $61 \%$ were female. $46.5 \%$ of the respondents were agedfrom 19 to 20 , whereas $43.5 \%$ were from 21 to 22 , followed by $9 \%$ and $1 \%$ were agedfrom 23-24 and over 24 years respectively. Among the respondents, the second-year students accounted for $38.5 \%$, followed by third-year students with $36 \%$ and the fourth year students with $25.5 \%$.

\subsection{Research instruments}

To collect data for addressing the research questions, this study employed two research instruments, namely the closed-ended questionnaire and the semi-constructed interview. All of the questionnaire items used to measure variables of this study were mainly adapted from Kikuchi and Sakai (2009), Alshehri (2013), and Huang (2016). The questionnaire was divided into three parts. The first part was used to obtain demographic information of the participants such as gender, age, and major. The second part included statements used to examine demotivating factors affecting students' English learning. 39 items designed in this part for answering Research Question 1were based on 5-point Likert scale ranging from 1 (strongly disagree) to 5 (strongly agree). The last part of the questionnaire including 15 items used for answering Research Question 2was about strategies which might be used to overcome demotivating factors. The interview had 7 questions. All the items of the questionnaire and the interview questions were translated into Vietnamese so that they were convenient and easy for the non-English majored students to complete.

\subsection{Data collection procedures}

After the close-ended questionnaire was developed and piloted, some revision was made to it. Later, the questionnaire copies were administered to the students in different departments. The purpose of the study and the instructions to complete the questionnaire were explained to all the students. For their convenience the researcher explained every question in Vietnamese as well. The students were given 5 days to complete the questionnaire. At first, questionnaire copies were administered to 235 students for the survey; but the number of questionnaire copiesreturned was 225.In addition, 25 copies could not be used because the respondents did not focus on the answers, the majority of the answers were only one choice, or the respondents missed too many statements, thus these copies were removed. Therefore, the participants of the survey were 235 , but the number of the respondents was 200, accounting for $85 \%$. After quantitative data was collected, 15 students were invited to participate in the interview. All the interviews took place during break time, within 15 minutes for each.

\subsection{Data analysis procedures}

Data obtained from the interview was analyzed by employing content analysis. Categories and themes relating to demotivating factors affecting students' English learningwere explored. All the students took part in the interview were coded as S1 to S15. Their key expressions related to the variables investigated were taken as notes on a sheet. Data obtained from the questionnaire was analyzed through the use of SPSS. Firstly, exploratory factor analysis of 39 items of demotivating factors was conducted using Principal Axis Factoring with the Promax rotation. Three factors with eigenvalues above 1 were identified, including Factor 1Teacher-related factors; Factor 2-Classroom-related factors; and Factor 3-Student-related factors. During the factor analysis, a total of 9 variables were removed due to failure to meet the factor loading requirement (loading cut-off above .40). That is why the final total number of items in the questionnaire was 30. Secondly, to assess the 
reliability, Cronbach's Alpha index was calculated to test the reliability of each variable in each factor after 9 variables were deleted. The following table describes the factors loadings on three factors and the total variance explained for each factor and Cronbach's Alpha indexes of the three factors.

Table 1 Factor Analysis of Demotivating factors and Cronbach's Alpha Indexes

\begin{tabular}{|l|l|l|}
\hline \multicolumn{1}{|c|}{ Factors } & \multicolumn{1}{|c|}{ Variables } & \multirow{2}{*}{ Cronbach's Alpha Index } \\
\cline { 2 - 3 } & $\begin{array}{l}\text { 9 Removed variables: 13, 14, 16, 26, 28, 29, 37, } \\
39,39\end{array}$ & \\
\hline Factor 1: Teacher-related & $\mathbf{1 4}$ Variables: 1,2,3,4,5,6,7,8,9,10,11,12, 15,17 & .962 \\
\hline Factor 2: Classroom-related & $\mathbf{9}$ variables: 18, 19, 20, 21, 22, 23, 24, 25, 27 & .907 \\
\hline Factor 3: Student-related & $\mathbf{7}$ variables: 33, 31, 35, 32, 34, 30, 36 & .883 \\
\hline KMO=.943 & \\
\hline The value for Bartlett's testSig. $=.000$ \\
\hline$\%$ of variance explained= 63.599
\end{tabular}

As it can be seen in Table 4.2, the factor analysis indicated a three-factor solution which explained $63.599 \%$ of the total variance. The three factors extracted were Factor 1 -Teacher-related factors, including 14 items which relate to teachers' behavior, teaching methods, teachers' feedback and grading; Factor 2-Classroomrelated factors including 9 items, representing learning content and materials and learning activities; and Factor 3-Student-related factors including 7 items related to students' confidence and intrinsic motivation.

Thirdly, for descriptive statistics, frequency $(\mathrm{F})$, mean (M) and standard deviation (St,D) were calculated. Frequency was first computed to examine demographic of the respondents. The mean score of the total items were ranked.

Based on calculated interval coefficient for four intervals in five points $(5-1=4)$, intervals with the range of $0.80(4 / 5)$ were arranged. The following criteria in the Likert type scale were used to interpret the data: Strongly disagree (1.00 - 1.80); Disagree (1.81 - 2.60); Undecided (2.61 - 3.40); Agree (3.41 - 4.20);

Strongly agree (4.21 - 5.00).Data obtained for addressingresearch question 2 was analyzed through the use of frequency and percentages. The strategy which obtained the highest percentage was put first in a table.

\section{RESULTS AND DISCUSSION}

\subsection{Results of the study}

7.1.1 Factors demotivating the students in learning EFL

Teacher-related factors

Table 2 Descriptive statistics for teacher-related factors

\begin{tabular}{|c|l|c|c|}
\hline No & 14 Items with M= 2.31 & M & St.D \\
\hline 1 & Teachers shout or get angry. & 2.19 & 1.179 \\
\hline 2 & Teachers ridicule students' mistakes. & 2.18 & 1.251 \\
\hline 3 & Teachers are not very friendly with students. & 2.28 & 1.304 \\
\hline 4 & Teachers show no emotion and enthusiasm while giving lectures. & 2.38 & 1.321 \\
\hline 5 & Teachers favor some students. & 2.36 & 1.232 \\
\hline 6 & Teachers rarely pay attention to less able students. & 2.42 & 1.332 \\
\hline 7 & Teachers do not prepare the les sons very well. & 2.14 & 1.139 \\
\hline 8 & Teachers seldom give feedback or only give negative feedback. & 2.28 & 1.122 \\
\hline 9 & Teachers rarely tests students' performance in class. & 2.43 & 1.087 \\
\hline 10 & Teachers never teach the students how to learn. & 2.40 & 1.296 \\
\hline 11 & Teachers' explanations are not easy to understand. & 2.39 & 1.235 \\
\hline 12 & Teachers' pronunciation of English is poor. & 2.24 & 1.221 \\
\hline 15 & Teachers' way of grading is unfair. & 2.19 & 1.149 \\
\hline 17 & Teachers rarely encourage the students to engage in learning activities. & 2.48 & 1.264 \\
\hline
\end{tabular}

Data displayed in Table 2 above revealed that the mean scores of the items ranged from 2.14 to 2.48 and the average mean score of 14 items was 2.31 , which means the students disagreed that teacher-related factors caused 
demotivation in EFL learning among students. These findings implied that most of the students agreed that their teachers' behavior and attitudes, teaching methods, ways of getting feedback and evaluation did not have negative effects on their learning.

Similarly, the findings of the interviews were also consistent with those of the questionnaire that revealed that a majority of participants (12/15) reported that teachers always had positive, friendly and helpful attitudes towards students. They said that teachers often paid attention to them.

"I think although I am not good at English, my teachers still pay attention to me. The teacher is not only interested in good students, but also in less able ones like me. I like that(S1)."

Moreover, most of the students did not find learning difficult(11/15) because they often got feedback from their teachers. They did not feel confused about what to do and what would be done. For example one student expressed:

"My English teachers often give feedback to me, so I really know whether my English is good enough. I know my progress in my learning (S5)." In addition to teachers' behavior, students paid much attention to teachers' competence and knowledge of English. When asked "Do your teachers' competence demotivate you?", 13 of the interviewees said that they were not skeptical about teachers' ability and qualification because their teacher had good pronunciation or knowledge of English. For example, S12 said:

"I really like my teacher's accent. She

Table 3 Descriptive statistics for classroom-related factors

\begin{tabular}{|c|c|c|c|}
\hline No & 9 Items with $\mathrm{M}=2.64$ & $\mathbf{M}$ & St.D \\
\hline 18 & Topics for speaking and reading are not interesting. & 2.63 & 1.179 \\
\hline 19 & The content of the passages in the course book is not close to life. & 2.53 & 1.211 \\
\hline 20 & Most of the lessons focus ongrammar. & 2.78 & 1.205 \\
\hline 21 & Most of the lessons focus on translation. & 2.64 & 1.139 \\
\hline 22 & There are almost no chances for me to communicate in English in class. & 2.93 & 1.345 \\
\hline 23 & The pace of lessons is not appropriate. & 2.50 & 1.094 \\
\hline 24 & Time allotment for learning activities is not enough. & 2.74 & 1.238 \\
\hline 25 & English learning tasks are too difficult. & 2.53 & 1.107 \\
\hline 27 & The class learning environment is always tense. & 2.52 & 1.178 \\
\hline
\end{tabular}

Data displayed in Table 3 above revealed that the mean scores of the 9 items ranged from 2.50 to 2.93; and the average mean score of the 9 item was 2.64, which means most of the students were undecided about the classroom-related factors. However, based on the mean scores, it can be seen in Table 3 that the students speaks English well and fluently. I wish I could speak English like her. Oh, it's not easy for me."

Particularly, nearly all of the students said that their teachers were rather fair in assessing the students. They all satisfied with the ways the teachers assessed them and marked their tests or assignments.

"My teachers often test our performance in class. They call us to go to the board to write something we have learned, or presented a topic in front of class. If we do well, we are given good marks (S4)"...."My teacher often give us assignments to do at home and in class he corrects the assignment and give marks (S9)."

However, a few students reflected that their teachers rarely encouraged the students to engage in learning activities while working in groups. Or, not many learning activities were organized during class. For example, S6 reported:

"I want my teacher to organize many activities for students to participate, especially pair work or group work. There are currently too few activities in the classroom."

It can be concluded that the findings of the questionnaire and interviews are in alignment with each other. Most of the students thought that teacher-related factors almost did not demotivate their learning. On the contrary, most of them were satisfied with what their teachers did for them.

\section{Classroom-related factors}

disagreed about four aspects that were related to the content, pace of lessons, tasks and learning environment (items 19, 23, 25, 27) with $\mathrm{M}=2.53,2.50,2.53$, and 2.52 respectively. It can be said that these aspects are closely related to teachers' practices in class. Teachers' friendly attitudes could really create a relaxing learning 
environment; teachers also played different roles in their instruction not as a knowledge conveyor as they used to be before. That is why the students did not think that the English learning tasks were too difficult and the pace of lessons was not appropriate. The mean scores of the other items showed that the students were undecided about these aspects (items 18, 20,21, 22 \& 24) with $\mathrm{M}=2.63$, $2.78,2.64,2.93 \& 2.74$ respectively. It might be because half of the students did not pay much attention to these aspects during the learning process. For example, regarding the aspect "the time allotment for learning activities was not enough", it can be inferred that half of the students thought that the time provided for learning activities during class was acceptable.

Regarding data collected from the interview, it was revealed that most of the students who were interviewed disagreed that classroom-related factors negatively affected their learning. 12 out of 15 students said that they were satisfied with the textbook and learning tasks. They had sufficient time to finish the tasks in class. Particularly, they thought that the pace of the lessons conducted by teachers were acceptable. For example, some students reported:

$$
\begin{aligned}
& \text { "During the English lessons, I learn a } \\
& \text { lot (S7)"..... "I think what we do in } \\
& \text { class is all right. We have time to } \\
& \text { prepare before we present in class or in }
\end{aligned}
$$

our group (S6)."...... "The teacher
asks us to write something before we speak; I never feel nervous or anxious when I have English lessons (S12)."

However, a few students said that learning tasks and activities were difficult for them to do. They sometimes did not have enough time to finish these activities. For example, S14 expressed:

"I think tasks and exercises are too difficult for me to do, especially when my teacher limits the time to do these tasks, I feel pressured because I cannot finish my exercises."

Besides, some students felt that the classroom environment was uncomfortable or even tense, which had significantly negative influence on their learning of English. Lastly, some other students found inadequate equipment facilities such as lighting, warming facilities or the Internet. For example, S8 expressed:

"The Wifi system is so bad, I cannot access the Internet."

It can be concluded that data collected from both the questionnaire and interviews reflected that classroomrelated factors did not demotivate them in their EFL learning, and that most of the students were satisfied with these aspects.

\section{Student-related factors}

Table 4 Descriptive statistics for student-related factors

\begin{tabular}{|l|l|c|c|}
\hline No & 7 Items with M= 3.39 & M & St.D \\
\hline 30 & I have difficulty in memorizing words and phrases. & 3.66 & 1.067 \\
\hline 31 & I do not know many English self-study methods. & 3.47 & 1.111 \\
\hline 32 & I cannot do as well on tests as my friends. & 3.39 & 1.097 \\
\hline 33 & I lack confidence in learning English. & 3.53 & 1.169 \\
\hline 34 & I lose my understanding of the purpose of studying English. & 3.30 & 1.186 \\
\hline 35 & I have difficulty in listening, reading, speaking and writing English. & 3.62 & 1.145 \\
\hline 36 & I feel nervous whenever I have English lessons. & 2.79 & 1.281 \\
\hline
\end{tabular}

Data displayed in Table 4 showed that the average mean score of the 7 items regarding student-related factors was 3.39. Based on calculated interval coefficient for four intervals in five points $(2.61$ - 3.40), it can be concluded that the students were undecided about these factors. Nonetheless, the students agreed that they had difficulty in memorizing words and phrases (item 30) with $\mathrm{M}=3.66$, did not know manyEnglish self-study methods (item 31) with $\mathrm{M}=3.47$, had difficulty in listening, reading, speaking and writing English(item 35) with $\mathrm{M}=3.62$, and lacked confidence in learning English (item 33) with $\mathrm{M}=3.53$. There was evidence that at least 4 student-related factors might demotivate the students themselves in their EFL learning. They really felt it difficult to learn English and sometimes were not confident. However, having English lessons did not make them nervous (item 36 ) with $M=2.79$. It can be said that although they felt learning English difficult, they still tried to come to class regularly.

Regarding data form the interview, 12 out of 15 students reported that their success of learning was greatly determined by themselves. That means if they were autonomous, confident and motivated, they could be successful in learning. However, many of them confirmed that they lacked confidence in learning English. Many of them felt learning English is difficult for them because they could not memorize words and phrases. For example, some students expressed: 
"I cannot memorize vocabulary and phrases in English although I tried to learn vocabulary in different ways such as learning by heart, learning by written words on the paper, or using post-it note to stick everywhere (S14).....”To me learning English skills is not easy for me. I have tried my best to come to school regularly (S12)"

It can be concluded that among 7 aspects relating to the student-related factor, four of them, as mentioned above, demotivated the students the most. They are nonEnglish majored students. They might encounter difficulties in learning because of their low proficiency. However, it seems that they did not receive much training of learning strategies from the teachers. That is why they thought they did not know many English self-study methods.

7.1.2Teachers' strategies used to overcome demotivating factors

Table 5 Descriptive statistics of motivational strategies

\begin{tabular}{|c|c|c|c|}
\hline No & Motivational Strategies & $\mathbf{F}$ & $(\%)$ \\
\hline 1 & Creating a pleas ant class room atmos phere. & 164 & 82.0 \\
\hline 2 & Being enthusiastic in teaching. & 155 & 77.5 \\
\hline 3 & Showing students that they care about the students'progress. & 147 & 73.5 \\
\hline 4 & Establishing a good relationship with students. & 146 & 73.0 \\
\hline 5 & Teaching students strategies for self-study. & 144 & 72.0 \\
\hline 6 & Providing face-to-face feedback to students about their progress. & 129 & 64.5 \\
\hline 7 & Drawing their students' attention to their strengths and abilities. & 128 & 64.0 \\
\hline 8 & Organizing activities that lead to the completion of whole group tasks. & 124 & 62.0 \\
\hline 9 & Encouraging students to participate in learning activities. & 121 & 60.5 \\
\hline 10 & Offering rewards in a motivational manner. & 119 & 59.5 \\
\hline 11 & Providing students with positive feedback. & 117 & 58.5 \\
\hline 12 & Selecting suitable learning activities for every student. & 115 & 57.5 \\
\hline 13 & Indicating to their students that she/hebelieves in their efforts to learn English. & 112 & 56.0 \\
\hline 14 & Giving students sufficient time to prepare for learning activities. & 109 & 54.5 \\
\hline 15 & Building the less on plans based on students'needs. & 88 & 44.0 \\
\hline
\end{tabular}

Table 5 presents the motivational strategies which were chosen by the students. All the items are placed in order from the highest to the lowest frequency and percentage. The results indicated that $82 \%$ of the students wanted their teachers to create a pleasant atmosphere in the classroom (Item 1 with $\mathrm{F}=164$ times). It is evident that a pleasant or relaxing classroom environment is always preferred by EFL students. The results also revealed that about three-fourths of the students preferred their teachers being enthusiastic in their teaching (item 2 with $\mathrm{F}=155$ ), caring about their students' progress (item 3 with $\mathrm{F}=$ 147), establishing a good relationship with students (item 4 with $\mathrm{F}=146$ ), and teaching students strategies for selfstudy (item 5 with $\mathrm{F}=144$ ). Obviously, the students preferred their teachers to pay attention to them. They wanted their teachers to teach them how to learn both inside and outside the class. The third group of strategies that was preferred by over $60 \%$ of the students includes providing face-to-face feedback to students about their progress (item 6 with $\mathrm{F}=129$ ), drawing their students' attention to their strengths and abilities (item 7 with $\mathrm{F}=$
128), organizing activities that lead to the completion of whole group tasks (item 8 with $\mathrm{F}=124$ ), and encouraging students to participate in learning activities (item 9 with $\mathrm{F}=121$ ). The remaining strategies were appreciated at a lower level. More than half of the participants chose those strategies. More specifically, those students preferred their teachers offering rewards in a motivational manner (item 10 with $\mathrm{F}=119$ ); providing students with positive feedback (item 11 with $\mathrm{F}=117$ ); selecting suitable learning activities for every student (item 12 with $\mathrm{F}=115$ ); indicating to their students that they believes in their efforts to learn English (item 13 with $\mathrm{F}=112$ ), and giving sufficient time to the students to prepare for learning activities (item 14 with $\mathrm{F}=109$ ). The aspect obtained the lowest frequency was building the lesson plans based on students' needs (item 15 with $\mathrm{F}=88$ ).

Data collected from the interviews revealed that students expected their teachers to do a variety of practices or strategies to foster their learning and to overcome demotivating factors. Most of the students paid attention to teachers' behavior and attitudes. They wanted 
their teachers to create a relaxing learning environment. For example, some students reported:

"I think that teachers' behavior is very important. In fact, this is what we expect from a teacher and I like studying with teachers who have good relationships with students (S1).", or "I want to study in a comfortable and pleasant environment. If the class is too serious, it will be boring and dull(S3)."

Particularly, all of the students when interviewed said that teachers' feedback was really important for them. They could learn from teachers' feedback and group work. For example, some students said:

“...I want my teacher to give me feedback in the class. In this way, Ifeel that my teacher cares about me and I will make more efforts and follow her feedback to become better (S11). ”; “....I like to work in groups because I can ask the others questions and share experience. Group work can facilitate my learning. In fact, if $I$ work individually, even if I know the answer, I do not know whether it is right or wrong (S13)......"

It can be concluded that all the fifteen strategies mentioned above are very necessary for the teachers to use to motivate the students in their learning EFL at PUD. All of the strategies were chosen by more than half of the students, except the last one. It is tantamount to the fact that whether the students are motivated or demotivated depends a lot on the strategies used by the teachers.

\subsection{Discussion}

\subsubsection{Factors demotivating students in EFL learning}

In terms of factors that may demotivate students in their EFL learning, three major factors including teacherrelated factors, student-related factors and classroomrelated factors have been investigated. The findings of the study are consistent with the findings of the studies conducted by Kikuchi and Sakai (2009) and Huang (2016) that showed that those factors relating to teachers' teaching methods, responsibilities and behaviors do not negatively affect the students. It is evident that the EFL teachers at PUD have implemented their roles and responsibilities rather well. Teachers' responsibilities in motivating students in their learning are really important.Their responsibilities are reflected through the use of strategies in their teaching practice, through their behavior and attitudes. Students cannot do everything by themselves without teachers' support. Teachers are always in a highly responsible position. Their actions have the ability to affect students in quite profound ways. It is essential that their responsibility is always taken very seriously(Dikilitaş\& Griffiths, 2017). The findings also implied that a few students were not satisfied with the teachers. Those students might be less able students. They might have encountered difficulties in their learning. Or, they might have low English proficiency.

Regarding classroom-related factors, the findings of the study revealed that most of the students did not agree that those factors demotivate their EFL learning. It can be said that the teachers might provide the students with the conditions and opportunities for exercising a degree of independence and autonomy. The lessons which the teachers brought to the students might be interesting and useful enough to motivate the students. Most of them were satisfied with the time allotment, level of difficulty of tasks and the learning environment. Obviously, EFL students need time for practice so that they can acquire both language knowledge and skills (Harmer, 2001). This task is easier to accomplish with relevant learning tasks in a pleasant learning environment with the support of modern learning equipment. By doing so, less able students may be more confident in their learning. It was evident that the teachers could land the students a regular helping hand to stay afloat (Sheerin, 1997).

In terms of student-related factors that affect the students in their learning, the findings of the study revealed that about three-fourths of the students thought that those factors relating to them really demotivated them in their learning. Those students thought that they lacked confidence in learning English and had difficulty in learning the four skills: listening, reading, speaking and writing, and in memorizing words and phrases. It can be said that factors relating to the students may be more important than those related to teachers and environment. That means students' intrinsic motivation is very important. The findings of the study are consistent with those of the study conducted by Meshkat and Hassani (2012)that showed that the students themselves decide their success or failure in EFL learning. It is undeniable that confidence is very necessary for any EFL student(Brown, 2002). If students are confident they may take risks in their learning and they may be active to involve in learning activities to practice English. The more practice they get, the better they will become a good English learner.

In conclusion, the findings of the present study revealed that student-related factors may demotivate students in learning English, but classroom-related factors and teacher-related factors may not. This findings of the current study support previous studies (Kikuchi \& Sakai 2009; Meshkat \& Hassani, 2012; Hamada \& Grafström, 
2014) that demotivating factors affecting students in English learning may include student-related factors. However, the findings of the study may conflict with Dornyei's investigation (1998) that revealed that the teacher might be the most common source of demotivation.

\subsubsection{Strategies Used to Overcome Demotivating Factors}

Another aim of the current study is to explore motivational strategies from the students' perspectives. The findings of the study revealed that according to the students, a variety of strategies that can be used to motivate them and create positive attitudes towards English learning among students. Most importantly, the students were in strong agreement with the strategy "creating a pleasant atmosphere in the classroom". That is because a pleasant and supportive classroom atmosphere is an indispensable motivational condition to create motivation among students (Dornyei, 2001). Moreover, a pleasant classroom means teachers and students have a good relationship and teachers' behaviors are highly appreciated by the students, leading to good cooperation in teaching and learning. In fact, students always want to be in a classroom where teachers are friendly and have good relationships with them.

The findings of the study also revealed that learning activities and tasks are also important factors used to motivate students in their learning. Interesting and relevant tasks really attract students and encourage them contribute to the discussion, which means students may learn a lot from those types of tasks. According to Dornyei (2001), students usually enjoy a task if they play an essential part in it. Whether a learning task is interesting or not depends on teachers' roles and responsibilities. Teachers should actively develop and stimulate students' motivation (Dornyei, 1998). It can also be said that the students expected their teachers not only to provide learning opportunities for them but also to facilitate the use of those opportunities. This point of view not only reflects the teacher's roles in a language class, but it also shows that the teacher must employ various strategies to enhance learning(Smith \&Erdoğan, 2008). Obviously, the use of motivational strategies can help students have a more positive attitude towards language learning. Sil's(2017) study finding revealed that a teacher must have the knowledge of effective motivational teaching strategies. The is sue which arises is what specific strategies that teachers should carry out to foster students' in-class learning and out-of-class learning. They should know how to help students to integrate both of these domains. Teachers' in-class instruction should promote students' autonomous learning not only in the classroom but outside the classroom as well. Students know how to apply what they learn from teachers in class, especially, for example, learning strategies in self-study. In this case, the role of the teacher is as a gap-filler of the mismatch between what is learned in class and what the students need to learn outside the class so that they will promote their autonomy.

\section{CONCLUSION AND IMPLICATIONS}

The present study was conducted to investigate demotivating factors affecting students in learning English at the Vietnamese tertiary level. This study has been done to reaffirm the fact that demotivating factors have negative effects on students' EFL learning. The findings of the study revealed that among teacher-related, classroom-related and student-related factors, studentrelated factors were perceived to have negative effects on students' learning. Those factors which obtained most of the students' agreement were that they had a lot of difficulties in memorizing words and phrases; they also encountered difficulties in different skills like listening, reading, speaking and writing English, eventually leading to their lack of confidence in learning English and consequently, making them lose motivation. Regarding motivational strategies, the students rated the strategies at different levels. Accordingly, students highly estimated the motivational strategies which relate to creating a pleasant atmosphere in the classroom. They also appreciated the impact of teacher behavior on their motivation such as showing enthusiasm to teaching English, caring about the students' progress, and establishing good relationship with them. Furthermore, students expressed more agreement with motivational strategies which are related to learner autonomy. This means students are more motivated when they are familiar with self-study guided by the teacher.

This study is meaningful for English teaching and learning in higher education because it provides important implications that may help improve the quality of teaching and learning English in Vietnamese higher education in general and at PUD in particular. Based on the findings, it is recommended that EFL teachers should find out different ways for students to memorize lessons, especially memorizing vocabulary. They should pay attention to fully develop different skills for students including listening, reading, speaking and writing logically and systematically through the use of easy to difficult learning activities and tasks. The responsibility of teachers is to create opportunities for students to communicate in English as much as possible through activities inside and outside the classroom. Finally, there are many strategies which motivate to learn English are 
appreciated by students such as creating a pleasant atmosphere in the classroom, showing enthusiasm for teaching English, showing students that they care about their progress, establishing good relationship with students, and teaching students self-study methods or encouraging them to explore the knowledge independently. Teachers should be interested in applying these strategies in their teaching so that the teaching and learning process may make bid achievement and success.

For EFL students, having motivations for or like learning English is not enough. Setting goals for learning at the first stage is necessary. After that, during the process of learning, they have to take risks, be imbedded in learning activities and practice English both inside and outside the class. Only by doing so, they be able to overcome demotivating factors and gradually achieve their goals in learning English.

The study has certainly achieved its purposes; however, limitations cannot be avoided. It is suggested that future research may be conducted with the participation of both students and English teachers to understand more about the impact of demotivating factors at other universities in similar contexts.

\section{REFERENCES}

[1] Brophy, J. (2004). Motivating students to learn (2nd ed.). Mahwah, New Jersey: Lawrence Erlbaum Associates.

[2] Brown, H. D. (1987). Principles oflanguage learning and teaching. (2nded.). Englewood Cliffs, NJ: Prentice Hall Regents.

[3] Brown, H. D. (2002). Strategies for success: A practical guide to learning English. New York: Longman.

[4] Chambers, G. (1993). Taking the 'de' out of demotivation.Language Learning Journal, 7, 13-16.

[5] Dikilitaş, K \& Griffiths, C. (2017).Developing language teacher autonomy through action research. Is tanbul: Palgrave Macmillan

[6] Dornyei,Z. (1998). Demotivation in foreign language learning. Paper presented at The TESOL '98 Congress, Seattle WA. March.

[7] Dörnyei, Z. (2001). Motivational strategies in the language classroom. Cambridge: CUP.

[8] Dörnyei,Z. (2009). The psychologyofsecond language acquisition. Oxford: Oxford University Press.

[9] Dornyei, Z., \&Ushioda, E. (2011).Teaching and researching motivation. Harlow, England: Longman/Pearson.

[10] Ersöz, A. (2004). Intrinsic motivation in English language teaching.Education and Science, 29(132), 6771.

[11] Gardner, R. C., \&MacIntyre, P. D. (1993).A student's contributions to second-language learning. Part II: Affective variables. Language teaching, 26(01), 1-11.

[12] Griffing, C. (2006). Student-teacher relationships: An exploration ofstudentmotivation. (Master's Thesis), the College at Brockport: State University of New York.

[13] Hamada, Y. (2011). Different demotivators for Japanese junior high and high school learners.Journal of Pan-Pacific Association of Applied Linguistics, 15(1), 15-38.

[14] Hamada, Y., \&Grafström, B. (2014).Demotivating factors in learning Japanese as a foreign language. Retrieved from https://core.ac.uk/download/pdf/1441903

[15] Harmer, J. (2001).The practice of English language teaching $\left(3^{\text {rd }} \mathrm{Ed}\right.$.). New York: Longman.

[16] Huang, D. (2016). A Study on the Application of Taskbased Language Teaching Method in a Comprehensive English Class in China.Journal of Language Teaching and Research, 7(1), 118-127.

[17] Khouya, B., Y. (2018). Students Demotivating Factors in EFL classroom: The case of Morocco. Advances in Language and Literary Studies, 9(2), 150-159.

[18] Kikuchi, K., \& Sakai, H. (2009). Japanese learners' demotivation to study English: A survey study. JALT Journal, 31(2), 183-204.

[19] McDonough, S. (1983).Psychology in foreign language teaching. London: George Allen \&Unwin.

[20] Meshkat, M., \&Hassani, M. (2012). Demotivating factors in learning English: the case of Iran. Procedia Social and Behavioral Sciences 31, 745 - 749.

[21] Rogers, A. (1986). Teaching adults. Milton Keynes: Open University Educational Enterprises Ltd.

[22] Sakai, H., \& Kikuchi, K. (2009).An analysis of demotivators in the EFL classroom. System: An International Journal of Educational Technologies and Applied Linguistics, 37(1), 57-69.

[23] Schunk, D.H. (1996). Learning theories: Aneducational perspective. NewJersey: PrenticeHall.

[24] Sheerin, S. (1997).An exploration of the relationship between self-access and independent learning. In C. N. Candlin (Ed.).Autonomy and independence in language learning (pp.54-65). New York: Longman.

[25] Tran, Thị ThuTrang, \& Baldauf, R. B. (2007). Demotivation: Understanding resistance to English language learning-The case of Vietnamese students. The Journal of Asia TEFL, 4(1), 79-105.

[26] Wigfield, A. \&Eccles, J. (2000).Expectancy-value theory of achievement motivation. Contemporary Educational Psychology, 25,68-81.

[27] Wlodkowski, R. (1985). Enhancing adultmotivation to learn. San Francisco: Jossey-Bass.

[28] Young, D. J. (1999).Affect in foreign language and second language learning. Boston: McGraw-Hill. 